\title{
The impact of COVID-19 induced lockdown on the changes of air quality and land surface temperature in Kolkata city, India
}

\author{
Nemai Sahani ${ }^{1}$ (D) Sudipto Kumar Goswami ${ }^{2} \cdot$ Arghya Saha $^{3}$
}

Received: 13 July 2020/Revised: 29 October 2020/Accepted: 3 November 2020/Published online: 13 November 2020

(C) Korean Spatial Information Society 2020

\begin{abstract}
The COVID-19 pandemic and related lockdown reduced the pollution level in the major megacities worldwide. The air pollution level of the city directly influences the air temperature and also land surface temperature (LST). In this paper, authors analyzed the impact of lockdown due to COVID-19 pandemic on the pollution level of the city and resulted LST. Single channel algorithm has been used to retrieve LST from Landsat Thematic Mapper satellite data. Pre-lockdown and postlockdown satellite data has been used to show the changes in LST due to lockdown. The air quality index of prelockdown and post-lockdown period of the city estimated based on seven pollutants such as $\mathrm{PM}_{2.5}, \mathrm{PM}_{10}, \mathrm{NO}_{2}, \mathrm{NH}_{3}$, $\mathrm{SO}_{2}, \mathrm{CO}$ and Ozone. The pollution level of the city and LST significantly decreased after lockdown is enforced. The pollution level of the major portion of the city before lockdown is moderately polluted $(95-153 \mu \mathrm{m})$ and after lockdown the satisfactory level of pollution level observed (33-45 $\mu \mathrm{m})$. The mean LST before lockdown is $28.76{ }^{\circ} \mathrm{C}$ (13 March, 2020) and it decreased down to $26.56^{\circ} \mathrm{C}$ after lockdown (30 April, 2020). There is a sharp decrease of low value of LST observed $\left(23.6-17.35{ }^{\circ} \mathrm{C}\right)$ in the city.
\end{abstract}

Nemai Sahani

nemai123@gmail.com

Sudipto Kumar Goswami

geo.sudipto@gmail.com

Arghya Saha

arghyasaha21@gmail.com

1 Independent Researcher, Bolpur, West Bengal, India

2 Department of Geography, Visva-Bharati, Santiniketan, West Bengal, India

3 Department of Geography, Bidhan Chandra College, University of Calcutta, Rishra, India
Keywords COVID-19 - Lockdown · Kolkata city · Land surface temperature $\cdot$ Air quality index

\section{Introduction}

The increase of pollution level in the city and pollution induced local climate change is became an important issue for the municipal authorities. At that time, individual cities and transnational municipal networks started to take actions for reducing emissions of greenhouse gases and other atmospheric pollutants [1]. The release of atmospheric pollution and rapid urbanization alter the heat balance of the earth surface and atmosphere. The increase of atmospheric pollution level in the city raised the temperature in both atmosphere and surface and this leads towards urban climate change. National governments and the emerging international regime for governing urban pollution and climate change showed little attention in these activities at that stage [2]. At first, municipal action on climate change was seen in a few pioneer cities, predominantly in North America and Europe, focusing on the challenge of climate change mitigation [3, 4]. Later the number of transnational municipal networks have grown and multiplied and more number of cities have become involved in addressing this issue. The earliest work on local climate policy in urban environment and governance was conducted in the mid-1990s [5, 6] and a large body of research work has been accumulated. Most of the research was focused on mitigation and individual case studies $[7,8]$, although there has been the initiation of work on urban climate adaptation in the global south [9].

In climatological and environmental studies, LST is a key variable. The reason is LST control the physical, chemical and biological processes on Earth [10]. It is 
related to surface energy balance and the integrated thermal state of the atmosphere within the planetary boundary layer [11]. Traditionally, LST was obtained from standard surface-air temperature by using sheltered thermometer 1.5-3.5 $\mathrm{m}$ above a flat, grassy, well ventilated surface. Many studies use LST as fundamental data in the study of environment and resources. Globally Satellite based surface temperature (LST) also known as skin temperature [12]. Satellite based LST products provide an estimate of the kinetic temperature of the earth's surface skin [13] which is the aggregate surface medium viewed by the sensor to a depth of about $12 \mu \mathrm{m}$. Skin temperature is the thermal emission of the earth surface and average effective radiative temperatures of various canopy and soil surfaces [14]. LST is called a key parameter in land surface processes because it is an indicator of climate change, controls the upward terrestrial radiation, surface sensible and latent heat flux exchange with the atmosphere [15]. On the other hand, surface heat fluxes can induce local convection in the boundary layer and produce changes in air temperature, surface winds, cloudiness and precipitation [15]. The LSTs acquired by satellite borne sensors and used for heat balance, climate modeling and global change monitoring studies [16]. The brightness temperature is calculated by Plank's law from the atmospheric radiances obtained from thermal infrared sensors [17]. The brightness temperature is then converted into LST using ground surface emissivity considering vegetation density, the roughness and thermal properties of the ground surface and water content of the soil [18].

Cities are specifically built up urban part is majorly experienced such effects of temperature rise $[19,20]$ and conversion of earthy materials to concrete materials, change of vegetation cover area to built up land, dumping of water in the urban area are the principal vectors of LST rise in the urban area. This phenomena gave birth to urban heat island effects [21]. World Bank [22] projected that by 2020 megacities will be increased significantly in the developing countries. Rise of LST or Urban heat island effect is one of the major consequences of urban growth and enhanced energy emission [23, 24]. Growing energy footprint is another issue because it possesses enough potentiality to discharge extra heat to the atmosphere triggering heat residues in heat balance [25]. This type of heat is generated by anthropogenic effects.

The coronavirus disease 2019 (COVID-19) outbreak, which started in the Hubei province of China in 2019, has now spread to 212 countries and 2 international conveyances by May 5, 2020. WHO declaring Europe as the epicenter of the disease on March 13 [26]. Warmer temperatures will slow the spread of the COVID-19 virus has been a point of much speculation. This hypothesis has led some European countries to take policies regarding on decreased transmission rates during the summer months and India will face smaller epidemics than American or European counterparts. However, no strong evidences support such claims, SARS-CoV-2 arrived later in warmer countries. The first case of the COVID-19 pandemic in India was reported on 30 January 2020 which was originating from China. As of May 5 2020, the Ministry of Health and Family Welfare have confirmed a total of 46,711 cases, 13,161 recoveries and 1583 deaths in the country [27]. The outbreak is declared as an epidemic in states and union territories and provisions of the Epidemic Diseases Act, 1897 have been invoked. For this reason, educational institutions and many commercial establishments have been shut down in all of the country. On 22nd March 2020, India observed a $14 \mathrm{~h}$ voluntary public curfew at the instance of the prime minister. This initiative followed up with lockdowns till 14 April. It was further expanded to an nationwide ongoing lockdown till 3rd May. After 3rd May, third phase of lockdown is further expanded for 2 weeks. West Bengal first confirmed COVID-19 case on 17 March 2020 in Kolkata. There are a total of 1259 cases, 133 deaths and 218 recoveries are confirmed by The Health and Family Welfare Department of Government of West Bengal as of 4 May 2020 [28]. The state government declared four districts, including Kolkata is red zones in the wake of the COVID-19 outbreak. The whole state has 348 containment zones, out of which Kolkata has 227 [29]. Since the lockdown, every activity needs special permission from various administration units and almost all the domestic and international travels have been either banned or monitored closely. This type of situation limits economic activities which is very much dependent on transport network. This long time nationwide lockdown is stranded the economic pace for a long time in near future. But there are more positive issues of this period which are truly important for the environment and people. During this lockdown period, air and noise pollution were reduced by $50-70 \%$ in Kolkata, according to data released by the Central Pollution Control Board (CPCB). The less commercial activity (only essential goods and healthcare) during the lockdown period improved the air quality in different parts of the city. The air quality monitoring station at Ballygunje in south Kolkata represent an AQI of 33 on 30 April, 2020, which is good in environmental parlance. At the same time, readings at the AQI stations of Bidhannagar, Jadavpur, Rabindra Sarobar and Victoria Memorial were 28, 29, 36 and 33 respectively. According to WBPCB, the average air quality reading across Kolkata was 20 on 29 April 2020, which indicates good sign. An AQI between 0 and 50 is considered good, 51-100 satisfactory, 101-200 moderately polluted, 201-300 poor, 301-400 very poor, 401-500 severe and AQI above 500 falls in the severe plus category. 
LST depends upon the character of land surface area. Different methods has been used to detect LST in different areas by scientific community such as Single channel method [30], Multi-channel method [31], multi angle method [32], Split window algorithm [33] and Artificial neural network [15]. In the present situation, Covid -19 pandemic and associated worldwide lockdown improved degraded environmental quality and reduce pollution level. Urban areas around the globe has been affected by heat island phenomenon, resulting from air pollution and concretized surface. Kolkata is an important metropolitan city of India trying to cope with the current situation like other parts of India. The present study attempt to explore the difference of LST of the city before and after total lockdown. In addition, authors are trying to find out the significant relationship with pollution level (AQI) and LST in the city.

\section{Study area}

Kolkata, geographically stretches from $88^{\circ} 17^{\prime} 20.0796^{\prime \prime}$ E to $88^{\circ} 27^{\prime} 33.8508^{\prime \prime} \mathrm{E}$ longitude and $22^{\circ} 27^{\prime} 1.224^{\prime \prime} \mathrm{N}$ to $22^{\circ} 37^{\prime} 58.461^{\prime \prime} \mathrm{N}$ latitude. It is located on the eastern bank of river Hooghly and at $128 \mathrm{~km}$ north of Bay of Bengal. Kolkata city is administrated under the jurisdiction of Kolkata Municipal Corporation covering the area about $185 \mathrm{~km}$. The city is now subdivided in 144 wards due to the administrative reason. The city itself is a district (smallest district of West Bengal) as well as capital of the state (Fig. 1).

Kolkata is the capital of the state of West Bengal in India was first started as a British settlement, is located on a flat terrain and tide dominated drainage outfalls. It is one of World's largest urban centers, which is Kolkata urban agglomeration or Kolkata Metropolitan Area (KMA). KMA has continuously expanded over the years and presently extends over 1851 square km. Kolkata Municipal Corporation has an area of 185 square kilometer and is divided into 144 wards [34]. The region around KMA is experienced high intensity precipitation during the monsoon months. Sometimes heavy rainfall results in high tide which is the usual source of urban flooding. Kolkata has a tropical wet and dry climate with an annual mean temperature of $26.8^{\circ} \mathrm{C}$ and monthly mean temperatures in the range of $19-30{ }^{\circ} \mathrm{C}$. A study in comparison of air quality data among four metropolitan areas in India indicates a higher pollution level in Kolkata in comparison to Mumbai and Chennai and close to Delhi [35]. The worst polluted traffic intersections double the city's average pollutants during busy hours [36]. The area receives most of its rainfall from the South West monsoon between June and September. Annual rainfall is about $1600 \mathrm{~mm}$ and highest rainfall usually occurs during the monsoon in the month of August. The study on storm patterns [37] shows peak rainfall intensities occur anywhere between 15 and 180 min after the start of rainfall which often occur two or more times in a day during the monsoon. A joint occurrence of high tide and high rainfall can bring the city to a decline, as occurred in 1978, 1999 and 2007 [38]. Kolkata is located in a coastal area and influenced by strong sea based disturbances, this city experiences an average wind speed of $7 \mathrm{~km} / \mathrm{h}$ throughout the year. The wind direction is mainly southeast and southwest [39] and average value of solar radiation recorded is $1428 \mathrm{~W} / \mathrm{m}^{2}$ [40]. Today most of the city's planned infrastructure has met only handful of people because large number of populations living in informal settlements without access to essential infrastructure. Kolkata is experiencing slower population growth rates than other cities in India, though demographic pressures remain high [41].

\section{Material and methods}

\subsection{Data sources}

Satellite data of Landsat 7 (ETM) of two periods such as before lockdown (13th March, 2020) and after lockdown (30th April, 2020) were collected from USGS Earth explorer official website (https://earthexplorer.usgs.gov/). These satellite imageries were pre-georeferenced to UTM zone 45 north projection with WGS 84 datum. Atmospheric and radiometric correction of satellite imageries were carried out by Erdas Imagine software. Boundary map of KMC was prepared from the data based on Census of India (2011) report. The estimation of LST based on single channel algorithm is completed with the help of Saga GIS software. The atmospheric air quality data are obtained from Central Pollution Control Board (CPCB) official website from Kolkata city and surrounding air quality monitoring stations (https://app.cpcbccr.com/ccr/\#/caaqmdashboard-all/caaqm-landing). The hourly data on suspended air particles such as particulate matter (PM2.5 and PM10), Nitrogen di-oxide $\left(\mathrm{NO}_{2}\right)$, ammonia $\left(\mathrm{NH}_{3}\right)$, Sulphur di-oxide $\left(\mathrm{SO}_{2}\right)$, Carbon monoxide $(\mathrm{CO})$ and Ozone $\left(\mathrm{O}_{3}\right)$ were collected and used to measure air quality index (AQI).

\subsection{Method}

\subsubsection{Method for retrieval of LST}

Different method are used to retrieve LST from satellite imagery. In this present study, single channel algorithm used to retrieve LST in Kolkata city. Single channel 


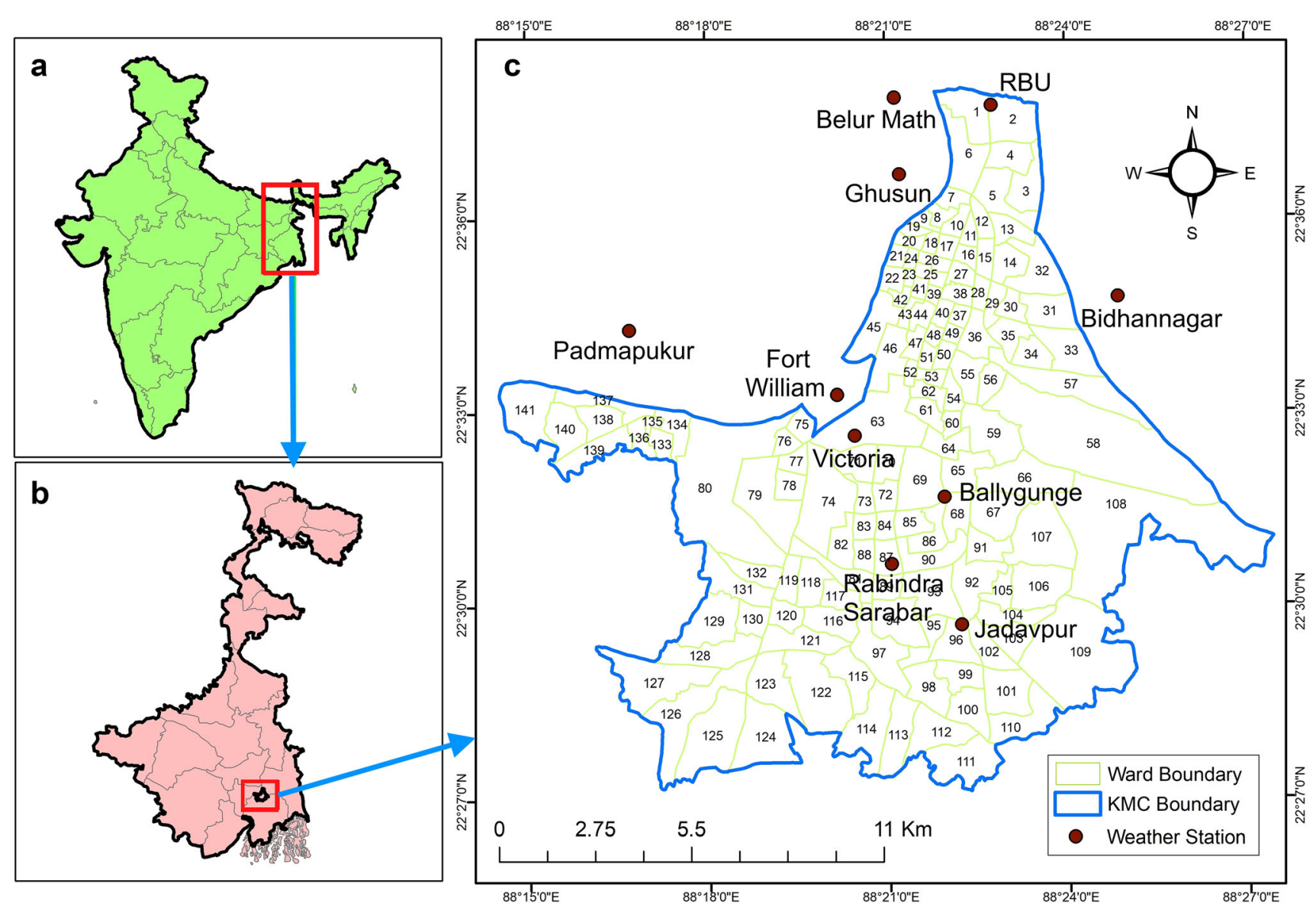

Fig. 1 Location of study area. a West Bengal within India, b study area within West Bengal, c study area

algorithm had advantages over other method and widely used to extract LST using single thermal band [42]. Single channel algorithm uses estimated atmospheric parameters to correct the atmospheric effect in a single channel to retrieve LST [43]. This method also called as model emissivity method [44] and it uses the radiance measure by the satellite in a single channel from an atmospheric window [45]. This method involves a simple inversion of radiometric transfer equation (RTE) and a theoretically accurate method for LST retrieval [42, 45].

The retrieval of LST from satellite imagery using single channel algorithm follows four step (Fig. 2) such as retrieval of TOA spectral radiance, conversion of spectral radiance to at-sensor brightness temperature, estimation of land surface emissivity and finally estimation of land surface temperature $[42,46,47]$.

\subsubsection{Step 1: Retrieval of TOA spectral radiance}

Top-of-Atmosphere (TOA) spectral radiance $\left(L_{\lambda}\right)$ estimated from Landsat data product with calibrated digital number $\left(Q_{c a l}\right)$ using radiometric rescale calibration coefficient or post-calibration dynamic ranges of spectral radiance $\left(L \min _{\lambda}-L \max _{\lambda}\right)$ of the bands [48]. The post calibration dynamic ranges of spectral radiance for thermal sensors (TM) was used to convert calibrated digital numbers $\left(Q_{\text {cal }}\right)$ to TOA spectral radiance $\left(L_{\lambda}\right)$. The spectral radiance $\left(L_{\lambda}\right)$ is calculated using equation-1 [49].

$L_{\lambda}=M_{L} Q_{\text {cal }}+A_{L}$

Landsat 7 band- 6 data ware converted into TOA spectral radiance $\left(L_{\lambda}\right)$ using radiometric rescaling coefficient such as band specific multiplicative rescaling factor $\left(M_{L}\right)$; $Q_{c a l}=$ digital number $(\mathrm{DN})$ of each pixel; and band specific additive rescaling factor $\left(A_{L}\right)$ [50].

\subsubsection{Step 2: Transmission of spectral radiance to at- sensor brightness temperature}

Brightness temperature $\left(T_{B}\right)$ is the radiance of the incoming electromagnetic radiation which is travelling upward from the top of the earth's atmosphere (Latif 2014). TOA spectral radiance $\left(L_{\lambda}\right)$ value has been converted into brightness temperature (T) using Eq. 2 [51]. 


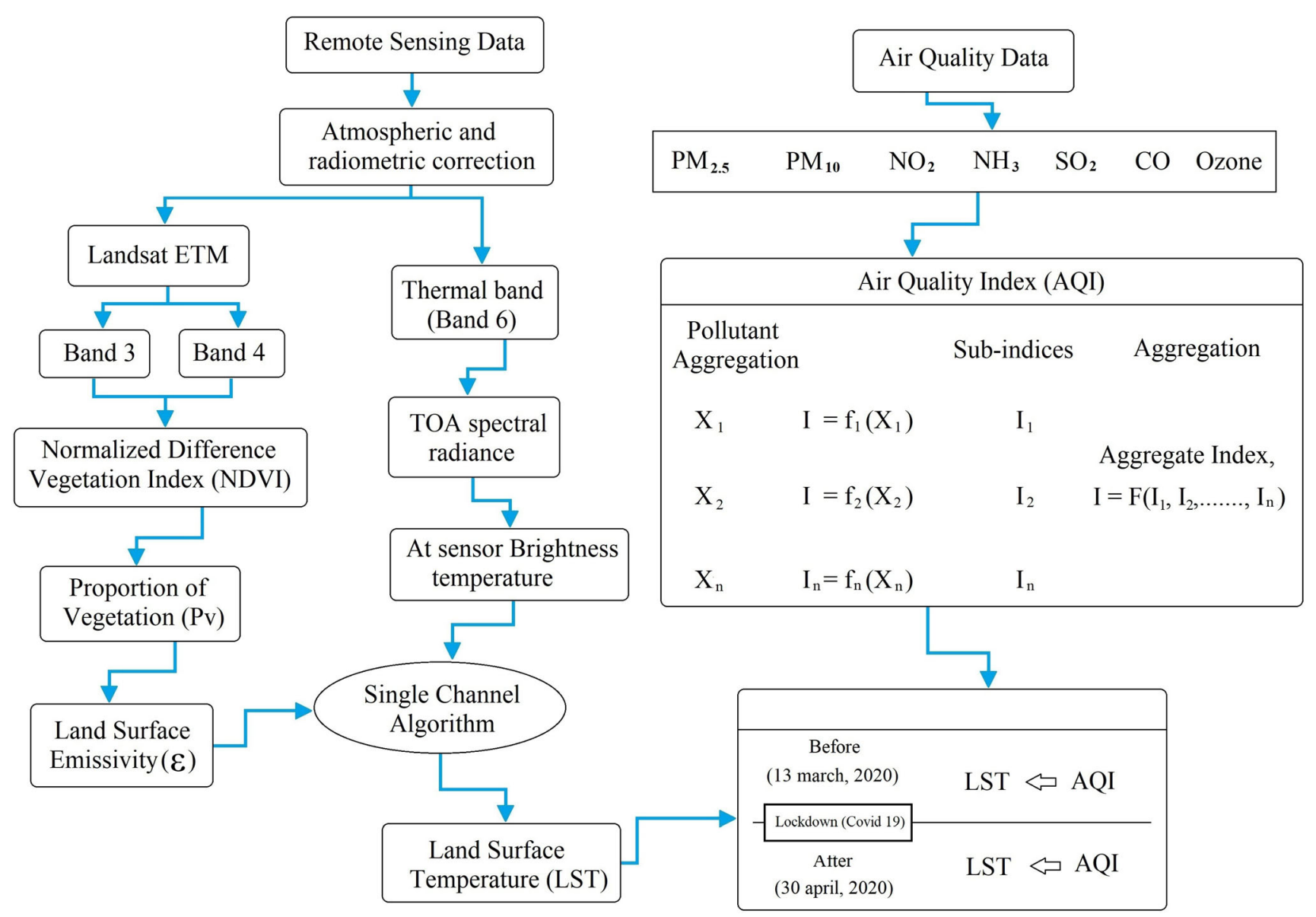

Fig. 2 Methodological framework of the study

$T_{B}=\frac{K_{2}}{L_{\lambda}\left(\frac{K_{1}}{L_{\lambda}}+1\right)}$

where $T_{B}=$ At satellite brightness temperature, $L_{\lambda}=$ TOA spectral radiance, $K_{1}$ and $K_{2}=$ thermal conversion constant.

\subsubsection{Step 3: Estimation of land surface emissivity}

Emissivity is the ability of a body to emit radiation [52]. In other word, it is radiative properties of an object [46]. Land surface emissivity $(\varepsilon)$ is a useful tool to understand the land surface energy budget from satellite data and also a fundamental element to estimate LST. The estimation of land surface emissivity $(\varepsilon)$ from brightness temperature $\left(T_{B}\right)$ follows three step such as (a) calculation of NDVI, (b) estimation of proportion of vegetation $\left(P_{V}\right)$ and $(c)$ estimation of land surface emissivity $(\varepsilon)$.

(a) Estimation of NDVI

To calculate land surface emissivity $(\varepsilon)$ the primary task is to estimate Normalized Difference Vegetation Index
(NDVI) using Red and NIR band of Landsat TM. NDVI calculated using Eq. 5 and the value ranges between -1 and 1 (Fig. 5).

$N D V I=\frac{\text { Band }_{R E D}-\text { Band }_{N I R}}{\text { Band }_{R E D}+\text { Band }_{N I R}}$

(b) Estimation of proportion of vegetation $\left(P_{V}\right)$

Proportion of vegetation or fractional vegetation cover can be obtained based on NDVI value. Proportion of vegetation $\left(P_{V}\right)$ calculated using following equation.

$P_{V}=\left(\frac{N D V I-N D V I_{\min }}{N D V I_{\max }-N D V I_{\min }}\right)^{2}$

where $P_{V}=$ Proportion of vegetation, $N D V I=$ Normalized Difference Vegetation Index, $N D V I_{\text {max }}=$ maximum value of NDVI and $N D V I_{\text {min }}=$ minimum value of NDVI.

(c) Estimation of land surface emissivity $(\varepsilon)$

$$
\varepsilon=0.004 * P_{V}=+0.986
$$


Land surface emissivity estimated based on Eq. 5 where $\varepsilon=$ Land surface emissivity and $P_{V}=$ Proportion of vegetation.

\subsubsection{Step 4: Estimation of LST}

LST has been calculated using at-sensor brightness temperature $\left(T_{B}\right)$ and land surface emissivity $(\varepsilon)$ using Eq. 8 $[47,51]$.

$L S T=\frac{T_{B}}{\left[1+\left(\lambda * \frac{T_{B}}{\rho} * \ln \varepsilon\right)\right]}$

where,

LST = land surface temperature in Kelvin scale,

$T_{B}=$ brightness temperature,

$\lambda=$ wavelength of emitted radiance,

$\rho=h \times \frac{c}{\sigma}\left(1.438 \times 10^{-2} \mathrm{mK}\right)$

$\left(\sigma=\right.$ Boltzman constant $=1.38 \times 10^{-23} \quad \mathrm{~J} / \mathrm{K}, \quad h=$ Planck's constant $=6.626 \times 10^{-34} \mathrm{Js}$, and $c=$ velocity of light $=2.998 \times 10^{8} \mathrm{~m} / \mathrm{s}$ ) and $\varepsilon=$ Land surface emissivity.

The LST estimated in Kelvin scale and converted into degree Celsius scale by subtracting 273.15 from each pixel value.

\subsubsection{Method for estimation of AQI}

Air quality index (AQI) is a composite index that transforms the weighted values of individual air pollutants into a single index [53]. In India, Central Pollution Control Board (CPCB) and Ministry of Environment and Forest (MoEF), government of India initiated the project National Air Quality Index (NAQI). The measurement of NAQI follows two steps: (1) formation of sub-indices of each pollutant and (2) aggregation of sub-indices to get an overall AQI [54]. To derive National Air Quality Index (NAQI) maximum operator approach used to remove uncertainty and eclipsing [55].

Step 1: Formation of sub-indices $\left(I_{1}, I_{2} \ldots I_{n}\right)$ for all pollutant variables $\left(X_{1}, X_{2}, \ldots, X_{n}\right)$ carried out using Eq. 7. Where $I_{i}=$ sub-index value, $X_{i}=$ pollutant concentrations.

$I_{i}=f\left(X_{i}\right), \quad i=1,2, \ldots, n$

Step 2: Aggregation of sub-indices performed based on overall index $(I)$ or AQI.

$I=F\left(I_{1}, I_{2}, \ldots, I_{n}\right)$

3.2.6.1 Sub-indices (Step 1) Sub-indices explains the changes of specific pollutant and related environmental consequences. Sub-indices is the relationship between pollutant concentration $X_{i}$ and corresponding sub-indices $I_{i}$. The relationship may be linear, non-linear and segmented linear. The relationship between I and X represented as-

$I=a X+\beta$

where $\mathrm{a}=$ slope of line, $\beta=$ intercept and $\mathrm{X}=0$. Based on 'linear segmented principle' sub-indices $\left(I_{i}\right)$ for a given pollutant concentration $\left(C_{p}\right)$ calculated based on following Eq. 10.

$I_{i}=\left[\left\{\left(I_{H I}-I_{L O}\right) /\left(B_{H I}+B_{L O}\right)\right\} \times\left(C_{P}-B_{L O}\right]+I_{L O}\right.$

where $B_{H I}=$ breakpoint concentration greater or equal to given concentration, $B_{L O}=$ breakpoint concentration smaller or equal to given concentration, $I_{H I}=\mathrm{AQI}$ value corresponding to $B_{H I}, I_{L O}=\mathrm{AQI}$ value corresponding to $B_{L O}, C_{P}=$ pollutant concentration.

3.2.6.2 Aggregation of sub-indices (Step 2) The subindices are combined in a simple additive form or weighted additive form. Different methods used to combine subindices and estimate Air quality index $(I)$ such as weighted additive form (Eq. 11), non-linear aggration form (Eq. 14), root-mean-square form (Eq. 15) and Min or Max operator (Eq. 16) $[53,54]$.

$I=\sum w_{i} I_{i} \quad($ For $i=1,2, \ldots, n)$

where $\sum w_{i}=1, I_{i}=$ sub-indices for pollutant $\mathrm{I}$, $n=$ number of pollutant variables, $w_{i}=$ weightage of the pollutant.

$I=\left[\sum I_{i}^{P}\right]^{\left(\frac{i}{P}\right)}$

where $p=$ positive real number $>1$.

Root-mean-square form

$I=\left\{1 / k\left(I_{1}^{2}+I_{2}^{2}+\ldots+I_{k}^{2}\right\}^{0.5}\right.$

Min or max operator

$I=\operatorname{Min}$ or $\operatorname{Max}\left(I_{1}, I_{2}, I_{3}, \ldots, I_{n}\right)$

\subsubsection{Method of other Landuse indices}

Normalized difference built-up index (NDBI) is useful method to extract urban buildup area. NDBI estimated using Eq. 15. NDBI value ranges between -1 and 1 . Higher value indicate build up areas and lower value means vegetation and negative value are water bodies. Normalized difference water index (NDWI) is used to detect the surface water content [56]. NDWI estimated using Eq. 16.

$N D B I=\frac{M I R_{\text {band }}-N I R_{\text {band }}}{M I R_{\text {band }}+N I R_{\text {band }}}$ 
$N D W I=\frac{\text { Green }_{\text {band }}-N I R_{\text {band }}}{\text { Green }_{\text {band }}+N I R_{\text {band }}}$

where $M I R_{\text {band }}=$ mid infrared band, $N I R_{\text {band }}=$ Near infrared band and Green $_{\text {band }}=$ green band of TM.

\section{Result and discussion}

The entire Kolkata city (KMC) is covered with multiple land use/cover types ranging from water bodies (Lake and Swamps) to vegetation cover (East Kolkata Wetland) and high density high rise buildings in the city center, interspersed with large areas covered with slums. The land use are classified into five categories namely Water body and Swamp, Greenery and open places, Public and Educational, Residential area and Commercial. The supervised classification was used to detect the relationship between land use/land cover and LST within Kolkata Municipal Corporation (KMC). It reveals that the spatial patterns of the city showing the concentration of three major land use classification-urban settlements including all the sealed areas as roads, vegetation patches including roadside trees and green fields and wetlands including all the ponds, lakes and canals. Urban settlements captured the whole KMC area covering $79 \%\left(161.91 \mathrm{Km}^{2}\right)$ of the total area [57]. The space occupied by the wetland is $4 \%\left(8.70 \mathrm{Km}^{2}\right)$ and vegetation patches are $35.31 \mathrm{Km}^{2}$. The area covered by vegetation patches increased slightly in the eastern part of Kolkata and in some scattered parts of southern Kolkata in comparison to the other parts of the study area. Across the entire study area, LST values increased from the outskirts towards the inner urban areas, where concentration of water body and green areas are relatively low. LST patterns were found as non-symmetrical and non-concentric, with high temperature zones clustered towards west of the central axis and beside the river Hooghly. There exists significant difference of LST of pre-lockdown and postlockdown period in the city (Fig. 3). The highest and lowest LST in before lockdown is $36.6{ }^{\circ} \mathrm{C}$ and $23.6{ }^{\circ} \mathrm{C}$ whereas after lockdown it decreased to $35.7^{\circ} \mathrm{C}$ and $17.3{ }^{\circ} \mathrm{C}$ respectively. Thus, the range of LST of postlockdown period decreased significantly due to the decrease in pollution level in the city (Figs. 4, 5, 6).

To understand the relationship and correlation of determination of LST with different Landuse indices such as Normalized Difference Buildup Index (NDBI), Normalized Difference Vegetation Index (NDVI) and Normalized Difference Water Index (NDWI), correlation graph prepared (Fig. 5). The value of NDVI varied from 0.333 to 0.518 . There exists negative relationship between NDVI with LST. The $\mathrm{R}^{2}$ value is $21.82 \%$ and it indicates lower dependency of NDVI in the determination of LST.
Figure 5 shows that low NDVI values were detected at the northern and central part of the study area, corresponding to the built up areas (such as buildings, roads etc.). NDVI was used as an index of vegetation abundance. This index is related to biomass, chlorophyll content and water stress. High NDVI values were discovered in certain patch of the study area, corresponding to green vegetation. The spatial pattern of NDVI appeared to be scattered and concentric. High NDVI values formed a belt in eastern and western direction and was scattered within study area, consistent with the distribution of parks and recreation sites. Build up areas and barren land has difference reflection pattern than vegetation cover. Figure 5 shows that NDBI is ranging from -0.933 to 0.559 where the $R^{2}$ value is $50.35 \%$. The coefficient of determination indicates that the NDVI highly controls the concentration of LST in the city. All over the city the concentration of higher NDVI value has been observed. The CBD of the city near Barabajar Region very high value of NDBI found. High value of NDBI was distributed principally in the northern part, but the areas with high NDBI expanded in the whole city, except some scattered patches. Eastern part of the city low NDBI value observed due to the existence of wetlands. In the study area, NDWI is ranging from -0.297 to 0.403 where the $R^{2}$ value is $12.43 \%$ (Fig. 5). NDWI calculated based on Landsat 7 satellite imagery and it reflects very high NDWI observed the places where water bodies are present. The surrounding places of Ganga River also influences the high concentration of NDWI in the city. Water bodies in Kolkata city are very sparse, only a few pockets of water body is left. Among all of these indices, the coefficient of determination is highest in the case of NDBI, because residential land use accounts $79 \%$ of all land use category, followed by vegetation and water body. Places with more temperature than average is decreasing in number due to the closure of commercial, industrial and transport activities during lockdown. Further study of general temperature profile of the study area from the LST images indicate that the temperature decreases from North and North-West to South and South-East direction (Fig. 3).

To understand and estimate the decrease of LST in different parts of the city, the pixel wise changes of the different temperature zone pre-lockdown and post-lockdown period were estimated (Fig. 7; Table 1). For this logical analysis five sequential temperature zone map prepared such as $>30{ }^{\circ} \mathrm{C},>28{ }^{\circ} \mathrm{C},>26{ }^{\circ} \mathrm{C},>24{ }^{\circ} \mathrm{C}$ and $<24{ }^{\circ} \mathrm{C}$ prepared. The decrease of pixel count of individual temperature zone significantly indicates the change of LST in pre-lockdown and post-lockdown period (Table 1). LST is influenced by many parameters such as solar incident radiation, angle of incidence of solar radiation, surface properties such as surface roughness, moisture content, extent of vegetation and air temperature. 


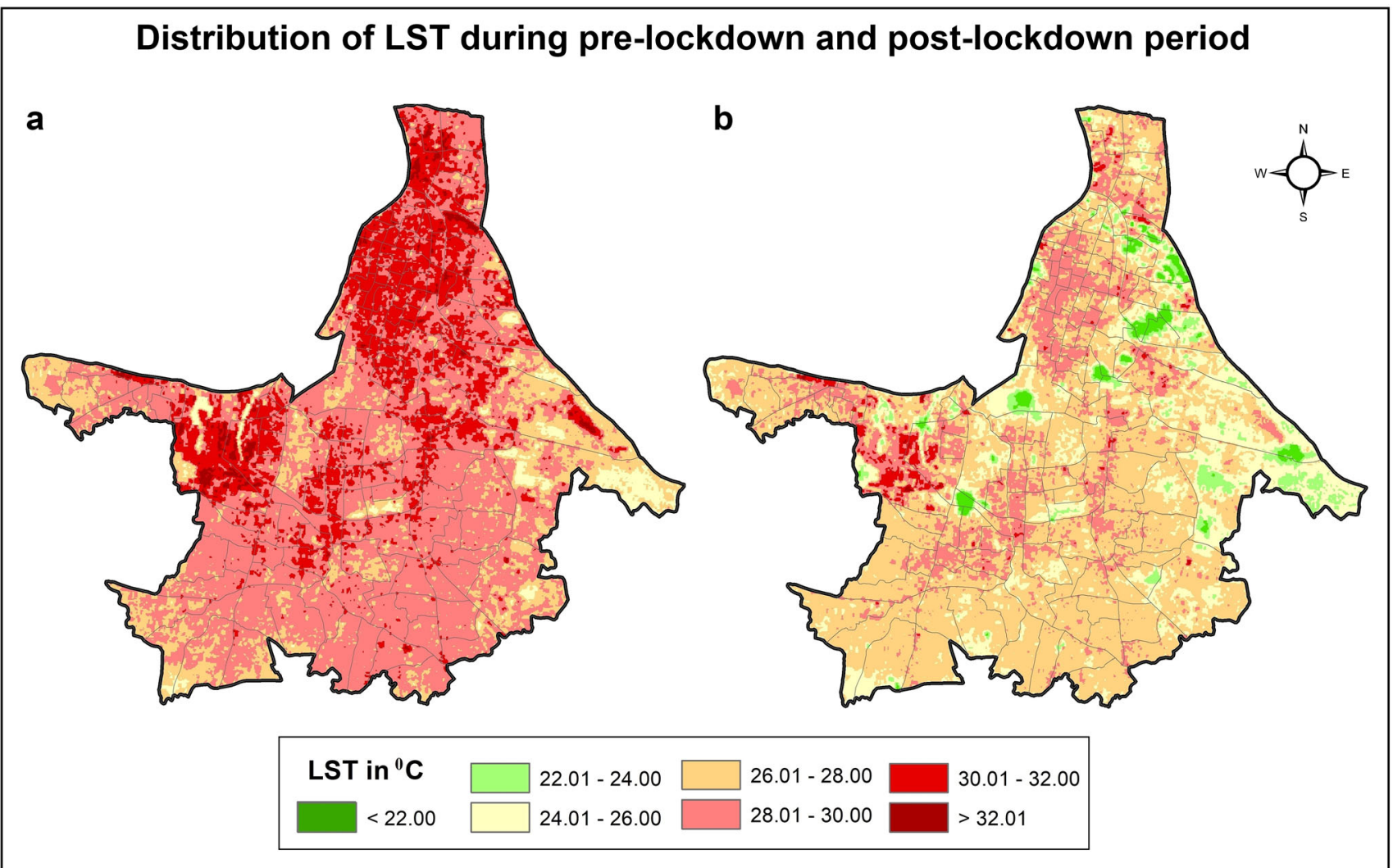

Fig. 3 Distribution of LST during pre-lockdown and post-lockdown period. a Pre-lockdown (13 March, 2010), b Post-lockdown period (30 April, 2020)

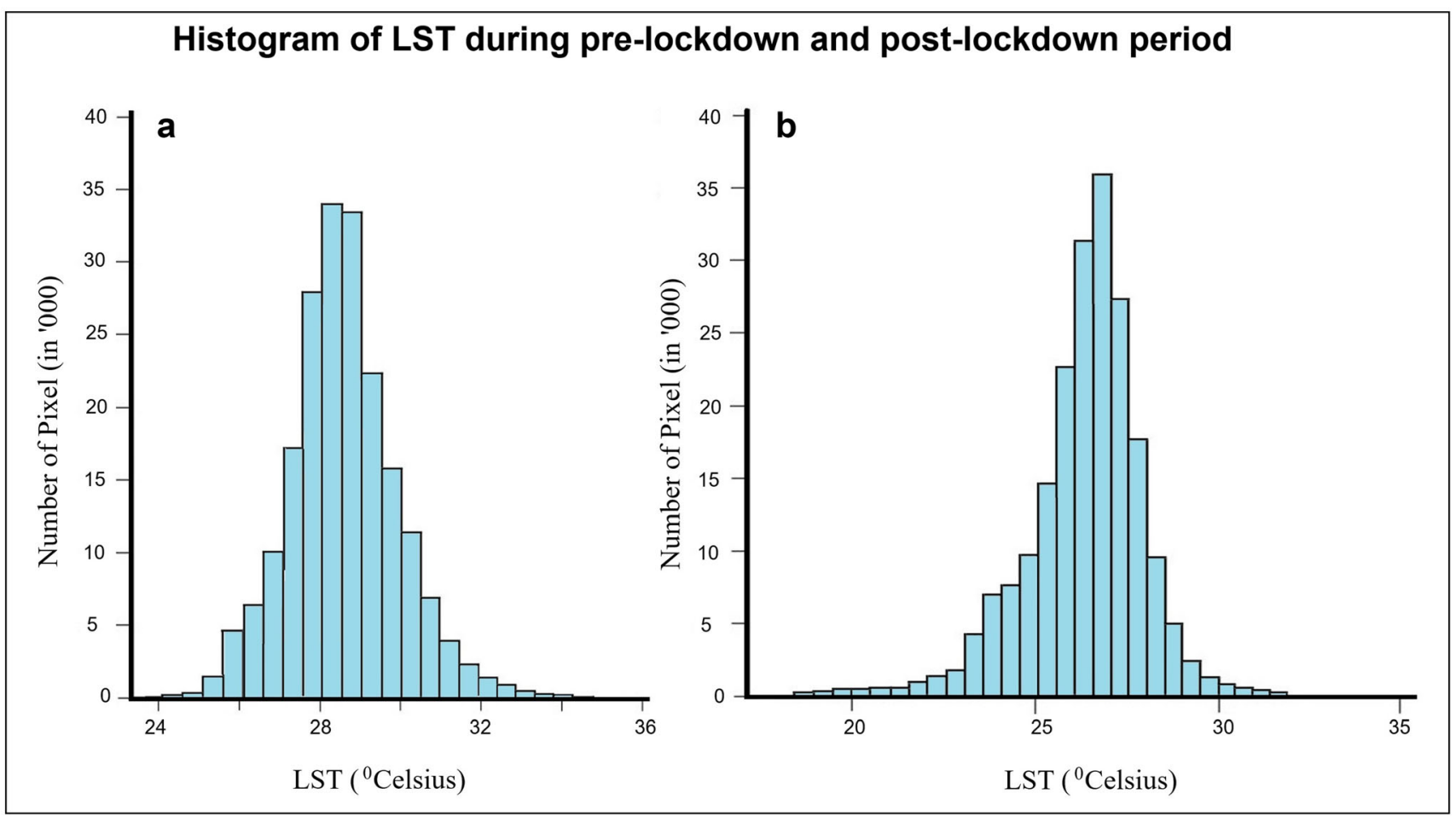

Fig. 4 Histogram of LST during pre-lockdown and post-lockdown period. a Pre-lockdown (13 March, 2010), b Post-lockdown period (30 April, 2020) 


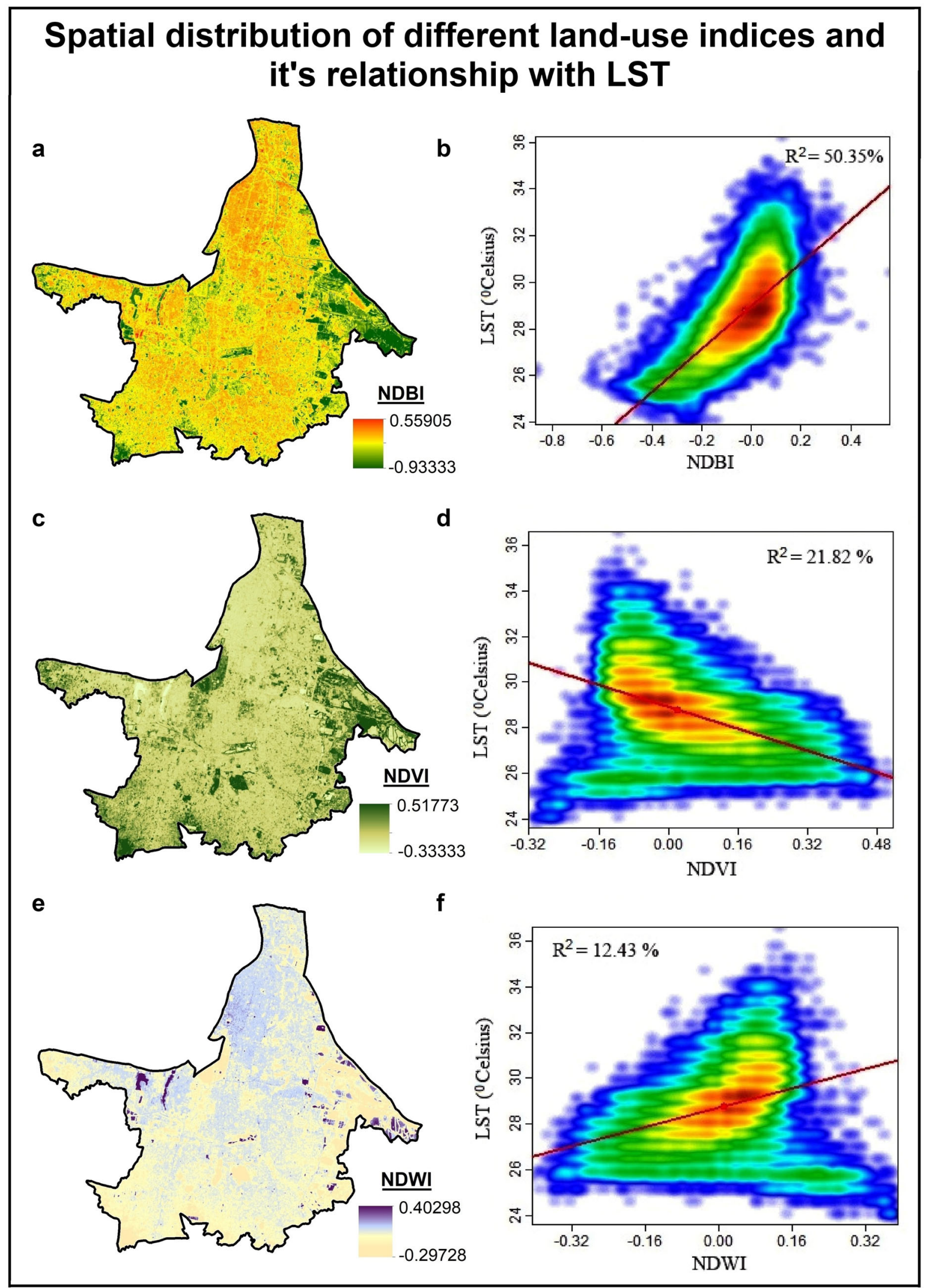

Fig. 5 Spatial distribution of different land-use indices and its relationship with LST. a Distribution of NDBI, b relationship of LST with NDBI, $\mathbf{c}$ distribution of NDVI, $\mathbf{d}$ relationship of LST with NDVI, e distribution of NDWI, $\mathbf{f}$ relationship of LST with NDWI 


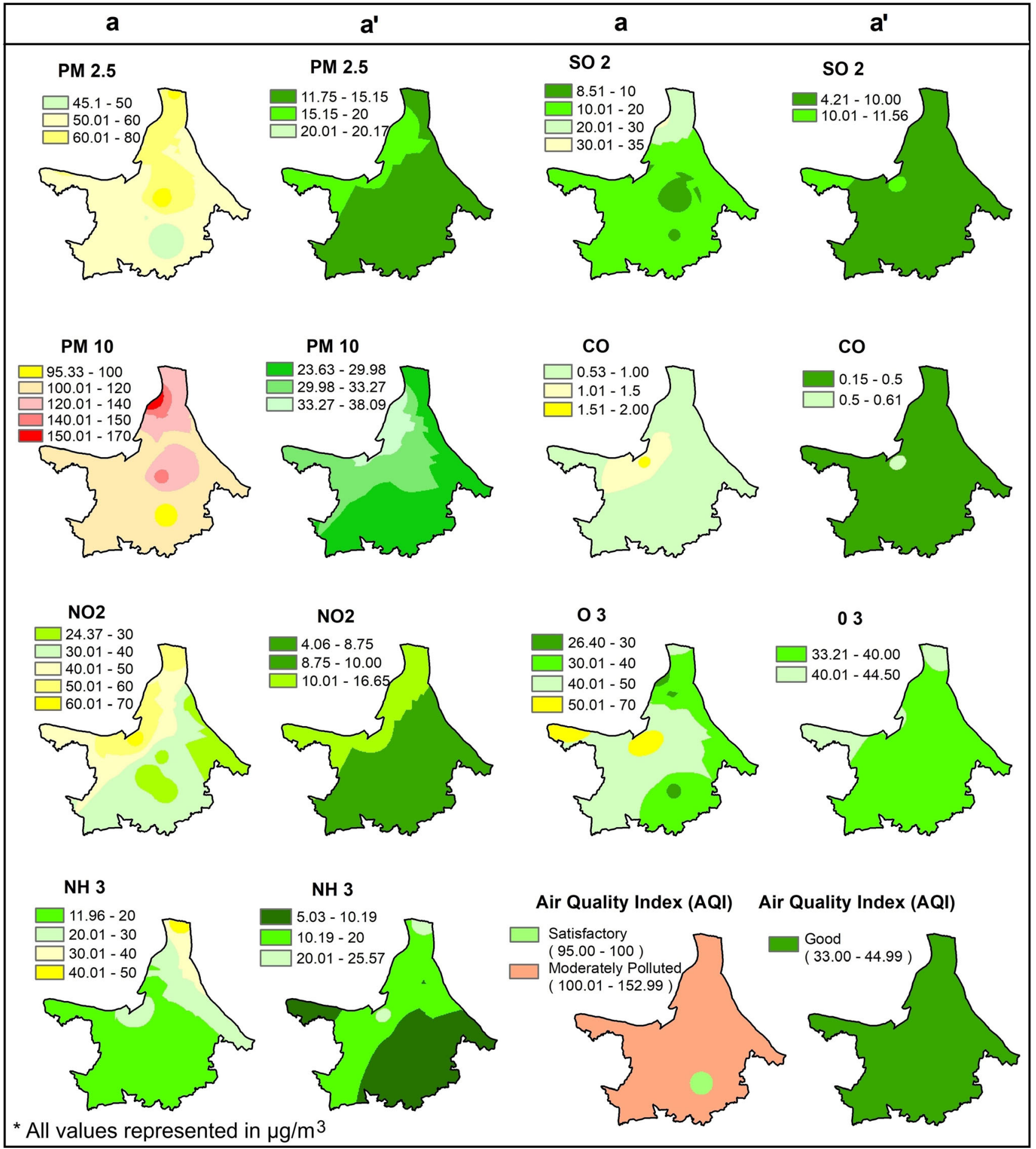

Fig. 6 Spatial pattern of air pollutant and air quality index (AQI). a Pre-lockdown period (13 March, 2010), a' Post-lockdown period (30 April, 2020)

The spatial change is experienced not only in the case of LST, but also in the concentration of $\mathrm{PM}_{2.5}, \mathrm{PM}_{10}, \mathrm{NO}_{2}$, $\mathrm{NH}_{3}, \mathrm{SO}_{2}, \mathrm{CO}$ and Ozone pollutants in air. In this study, 10 important weather station have been selected for data collection of pollution. Sources of air pollutants can be classified as primary and secondary sources. Primary pollutants are identified $\left(\mathrm{PM}_{2.5}, \mathrm{PM}_{10}, \mathrm{NO}_{2}, \mathrm{NH}_{3}, \mathrm{SO}_{2}, \mathrm{CO}\right)$ from the anthropogenic interference like power generation, automobile exhausts, factories, agricultures, airplanes etc. On the other hand Ozone (03) has been considered as a 


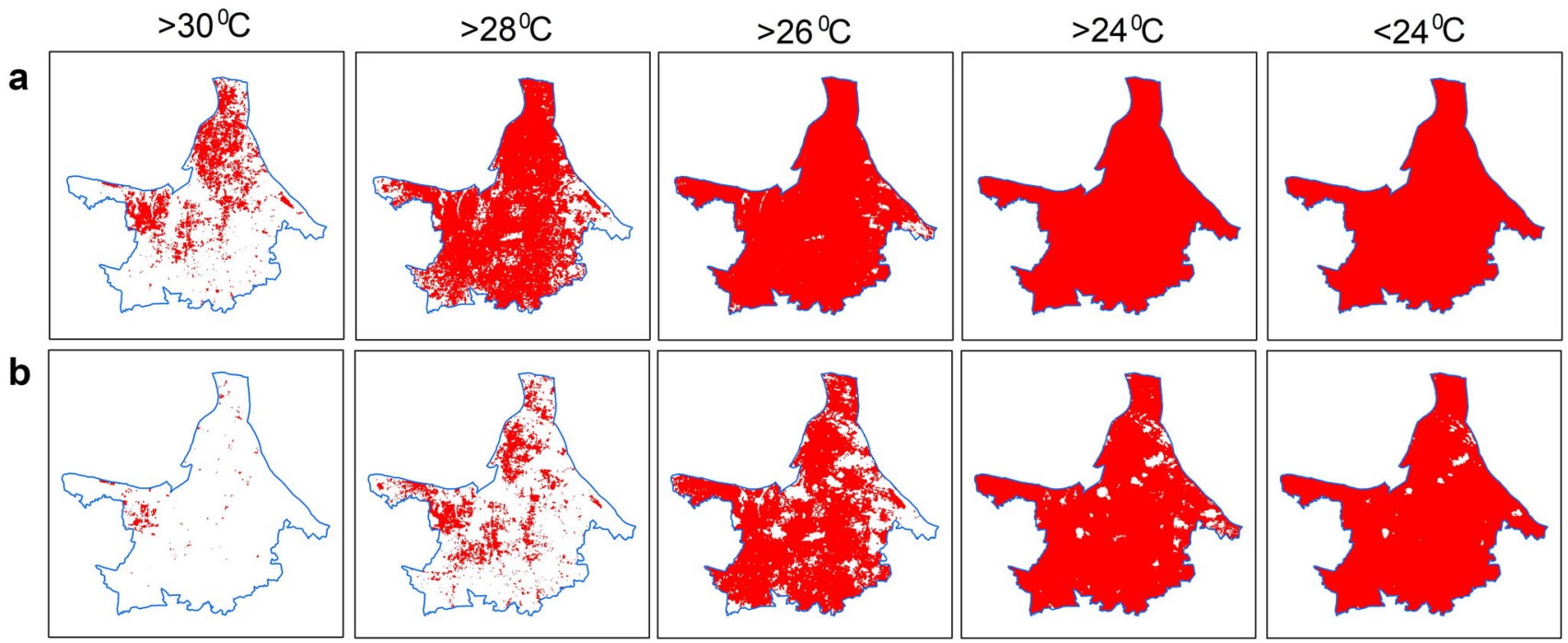

Fig. 7 Spatial variation of LST in different temperature zone. a Pre-lockdown period, b post-lockdown period

Table 1 Changes of LST of different temperature zone in $\mathrm{KMC}$

\begin{tabular}{llll}
\hline LST zone $\left({ }^{\circ} \mathrm{C}\right)$ & Pre-lockdown (13 March, 2020) & Post-lockdown (30 April, 2020) & Loss of pixel \\
\hline$>30$ & 43,703 & 3285 & 40,418 \\
$>28$ & 161,420 & 37,930 & 123,490 \\
$>26$ & 199,743 & 155,365 & 44,378 \\
$>24$ & 205,804 & 194,395 & 11,409 \\
$<24$ & 205,806 & 199,534 & 6272 \\
\hline
\end{tabular}

secondary sources, which is formed with interaction between primary pollutants (SEPA). The atmosphere can also be polluted by particles material other than gaseous pollutants. These particles (either in fluid, in solid state or in suspension), have a divergent size and composition and are sometimes called aerosols. They are often categorized as 'floating dust', but are best known as particulate matter (PM). Particulate matter (PM) is not a single pollutant, but rather is a mixture of many chemical components. It is a composite mixture of solids and aerosols mixture of small dry solid fragments, droplets of liquid and solid cores with liquid glazing. Most of the particles differ widely in shape, size and chemical composition, and may include inorganic ions, metallic compounds, elemental carbon, organic compounds, and compounds from the earth's crust. Particles are defined by their diameter for air quality regulatory purposes. Those with a diameter of 10 microns or less $\left(\mathrm{PM}_{10}\right)$ are inhalable and can persuade adverse health effects. In every urban center, these particulate matters (PM) take the most important position in all the other air pollutants. In Kolkata city, concentration of both particulate matters $\left(\mathrm{PM}_{2.5}\right.$ and $\left.\mathrm{PM}_{10}\right)$ were intensive before lockdown. In both the cases, high intensity of suspended particles concentrated in northern and middle part of the city on 13th March. After that 30th April experimental sample shows the drastic change of particle matters in the city due total locked down. This positive change of air quality encouraged for a healthy breathing condition in the city. The other elements of air pollution like $\mathrm{NO}_{2}, \mathrm{NH}_{3}$, $\mathrm{SO}_{2}, \mathrm{CO}$ and secondary Ozone gas made a drastic down fall between these two consecutive dates of locked down (Table 2). So, at a glance it has been very clear that peripheral eastern side of Hugli River, which has been more pollution prone due to industrial activities (Fig. 6). As well as, central part of city especially Burrabazar, Raja Bazar, Kankurgachi, Bowbazar, Ballygunge, Taltala, Tangra, Lalbazar, Esplanade and Park Street experienced intense traffic congestion on a normal day. General trend shows that Outer skirts of the city has been less polluted than the central and northern part of the city in every pollution parameters (Fig. 6). It can be easily rectify that outer growth of the present Kolkata city has more over residential in pattern rather than commercial or industrial. Therefore, older section of Kolkata is more congested as well as catalyst of increasing air pollution. At the end, over all air quality index (AQI) has been made from the database of ten sample zones on different pollutant parameters. Significantly over all city reflect moderately polluted (100.01-152.99) on the date before locked down (13th march). In 30th April air quality index (AQI) has been 
Table 2 Air quality index (AQI)

\begin{tabular}{lllllllll}
\hline Station & $\mathrm{PM} 2.5$ & $\mathrm{PM} 10$ & $\mathrm{NO}_{2}$ & $\mathrm{NH}_{3}$ & $\mathrm{SO}_{2}$ & $\mathrm{CO}$ & Ozone & AQI \\
\hline 13-Mar, 2020 & & & & & & & & \\
Ballygunge & 153 & 132 & 27 & 3 & 9 & 31 & 30 & 153 \\
Bidhannagar & 79 & 99 & 35 & 6 & 19 & 30 & 13 & 108 \\
Fort William & 87 & 104 & 57 & 6 & 13 & 34 & 24 & 105 \\
Jadavpur & 85 & 92 & 28 & 5 & 10 & 33 & 20 & 95 \\
RBU & 139 & 121 & 66 & 11 & 28 & 30 & 31 & 140 \\
Rabindra Sarabar & 87 & 104 & 12 & 4 & 13 & 34 & 22 & 101 \\
Victoria & 96 & 106 & 67 & 7 & 17 & 84 & 36 & 103 \\
Belurmath, Howrah & 67 & 93 & 74 & 6 & 32 & 33 & & 96 \\
Ghusuri, Howrah & 161 & 160 & 58 & 4 & 46 & 45 & 11 & 151 \\
Padmapukur, Howrah & 114 & 100 & 44 & 5 & 20 & 30 & 32 & 104 \\
30-Apr, 2020 & & & & & & & & \\
Ballygunge & 27 & 40 & 8 & 1 & 6 & 14 & 46 & 40 \\
Bidhannagar & 30 & 28 & 7 & 3 & 9 & 17 & 46 & 40 \\
Fort William & 32 & 35 & 14 & 2 & 6 & 16 & 49 & 44 \\
Jadavpur & 27 & 31 & 12 & 2 & 7 & 20 & 40 & 33 \\
RBU & 32 & 28 & 24 & 6 & 9 & 10 & 50 & 45 \\
Rabindra Sarabar & 23 & 27 & 9 & 2 & 7 & 10 & 49 & 38 \\
Victoria & 29 & 32 & 17 & 6 & 9 & 27 & 39 & 33 \\
Belurmath, Howrah & 23 & 29 & 23 & 3 & 10 & 13 & & 34 \\
Ghusuri, Howrah & 41 & 51 & 20 & 2 & 9 & 13 & 46 & 42 \\
Padmapukur, Howrah & 39 & 32 & 14 & 1 & 9 & 19 & 53 & 45 \\
\hline
\end{tabular}

show very good result (33.00-44.99). This upgraded quality has positively regenerate pure inhalable air in the city.

There is significant change in LST between 13th March and 30th April has been found. In the Fig. 3, Spatial variation of the temperature between local pockets are significantly low than it was on 13th March. The average temperature of Kolkata city is $28{ }^{\circ} \mathrm{C}$ on both dates. Figure 3 shows stronger LST intensity in 13th March than in 30th April. The figure also shows that larger areas that were affected by high LST was on 13th March, before lockdown was initiated. The spatiotemporal change between these to pre-lockdown and post-lockdown period is not only obvious in the changing pattern of LST, but also witnessed substantial downfall of the pollutants. Especially, during the study period $\mathrm{PM}_{2.5}, \mathrm{PM}_{10}, \mathrm{NO}_{2}, \mathrm{NH}_{3}, \mathrm{SO}_{2}, \mathrm{CO}$ and Ozone concentration have shown significant declining trends. Average concentration of $\mathrm{PM}_{2.5}$ and $\mathrm{PM}_{10}$ have reduced by about 14.787 and 29.853 from 57.876 and 117.524 respectively. Other pollutants that have shown considerable variation between pre and during lockdown are $\mathrm{NO}_{2}$ (10.549 from 43.167), $\mathrm{NH}_{3}$ (11.373 from 22.625) and $\mathrm{SO}_{2}$ (8.147 from 15.857). However for $\mathrm{NH}_{3}$ and $\mathrm{SO}_{2}$ the reduction have counted are low in comparison to the others. In urban areas, $\mathrm{NO}_{2}$ and $\mathrm{CO}$ is mainly emitted from combustion practice from road traffic, particularly diesel and smaller concentration of gasoline, vehicles, manufacturing industry and power plants. The concentration of $\mathrm{SO}_{2}$ in Kolkata city is also high because of its activity as river port. Majority of $\mathrm{SO}_{2}$ starts off from shipping emissions (large cargo ships, cruises and ferries). On the other hand, $\mathrm{NH}_{3}$ originated mainly from agricultural sources [58]. So concentration of this particular gas is much below the acceptable limit. However, the concentration of $\mathrm{NH}_{3}$ is significantly decreased during the lockdown phase because petrol engine vehicles comprise most of the Urban $\mathrm{NH}_{3}[59,60] .8 \mathrm{~h}$. average daily maximum concentration of $\mathrm{O}_{3}$ (38.587 from 40.069) in the study period shows negligible decrease. The concentration of Ozone $\left(\mathrm{O}_{3}\right)$ increases especially in the industrial and transport dominated locations which are out of operation during lockdown period. Overall, AQI (Air Quality Index) has been changed significantly from moderately polluted (100.01-152.99) to Good (33.00-44.99) air quality. This is a clear indication that substantial improvement of the air quality is due to the implementation of air quality control measures in lockdown period.

There exists the differentiation in changes of LST behaviour in different functional region of the KMC. The landuse pattern of the city also determines the nature of LST. Thus for the detailed explanation micro level study carried out based on different landuse and functional zone within study area such as residential area, industrial area, commercial area (CBD), traffic congestion area and 
Fig. 8 Location of sample zones for LST change detection in the city. a Zone 1 , b zone 2 , c zone 3 , d zone 4 , e zone 5 , and f zone 6

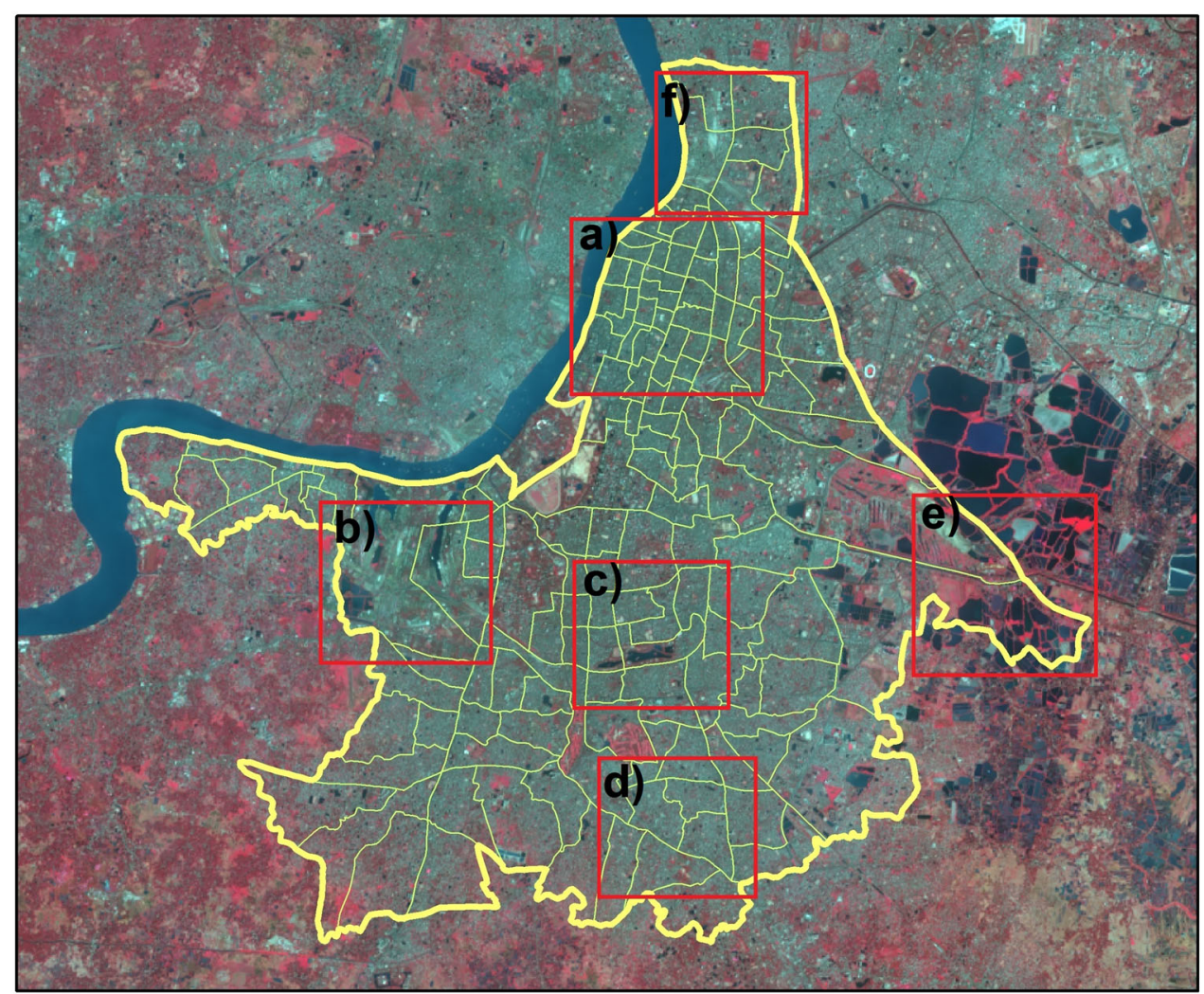

wetlands areas. Thus six functional zone selected for further explanation (Fig. 8).

Zone 1 located in the northern corner of the city and it comprising ward no. 5 to ward no. 57 (Fig. 9a). Most of the land use classification in this part is dominated by commercial, residential and mixed residential land use. There are also a few green area and dispersed industrial land use is found. Mixed residential area included administrative and commercial activities along with residential land use. North Kolkata is the oldest part of the city and for this reason, residential density is very high. There are a number of slums sheltering large number of people also. In most cases, slums and developed residential areas are overlaps. The vertical development of residential land use in recent years led to mixed land use phenomena. Central Business District (CBD) of Dalhousie, Chowringhee and commercial center of Burrabazar are part of zone 1 where higher LST observed. There is significant decrease of LST observed in this zone due changes of atmospheric pollution level. Zone 2 is located in South west part of the city (Fig. 9b) and industrial landuse is common in this area. The two main neighborhoods of this zone are Garden Reach and Behala. These two are comprising ward no. 80; 133-141 and 118-132 respectively. These are the two oldest neighborhoods of Kolkata and home of several major industries. Other major land use category is residential land use. The average decrease of LST in this zone is highest in comparison to other zones. Waterbody and public parks generally showing lower temperature than industrial land use. Zone 3 of Kolkata Municipality is the part of south Kolkata and expanded from ward no. 65 to ward no. 105 (Fig. 9c). There are neighborhoods namely Tiljala, Bhowanipore, Ballygaunge, Park Circus etc. Shortage of residential lands forced people to move in these swamp areas. Recently, land shortage in Kolkata attracts people in these areas which was upgraded and now became the prime plots for high-rise expansion, commercial as well as residential complexes. There are a number of healthcare facilities are available in Mukundapur, Ruby and adjacent areas and became a medical hub. Changing transport and communication system as well as government planning is changed the entire area. In the lockdown period, there are a drastic change in LST composition is found in this region (Fig. 9c). The changes of LST is prominent in landuse with water bodies and vegetation cover Zone 4 is located in South Kolkata and expanded from ward no. 94 to ward no. 114 (Fig. 9d). Neighborhoods of this area are Tollygunge, Bansdroni, Jadavpur, Garia etc. These areas are famous for residential, commercial and educational land use. Tollygunge and Garia are wellknown for commercial centers, restaurants, daily markets etc. During lockdown period, commercial and transportation activities were shut down which is the main reason behind the decrease in LST. Zone 5 is a part of East 


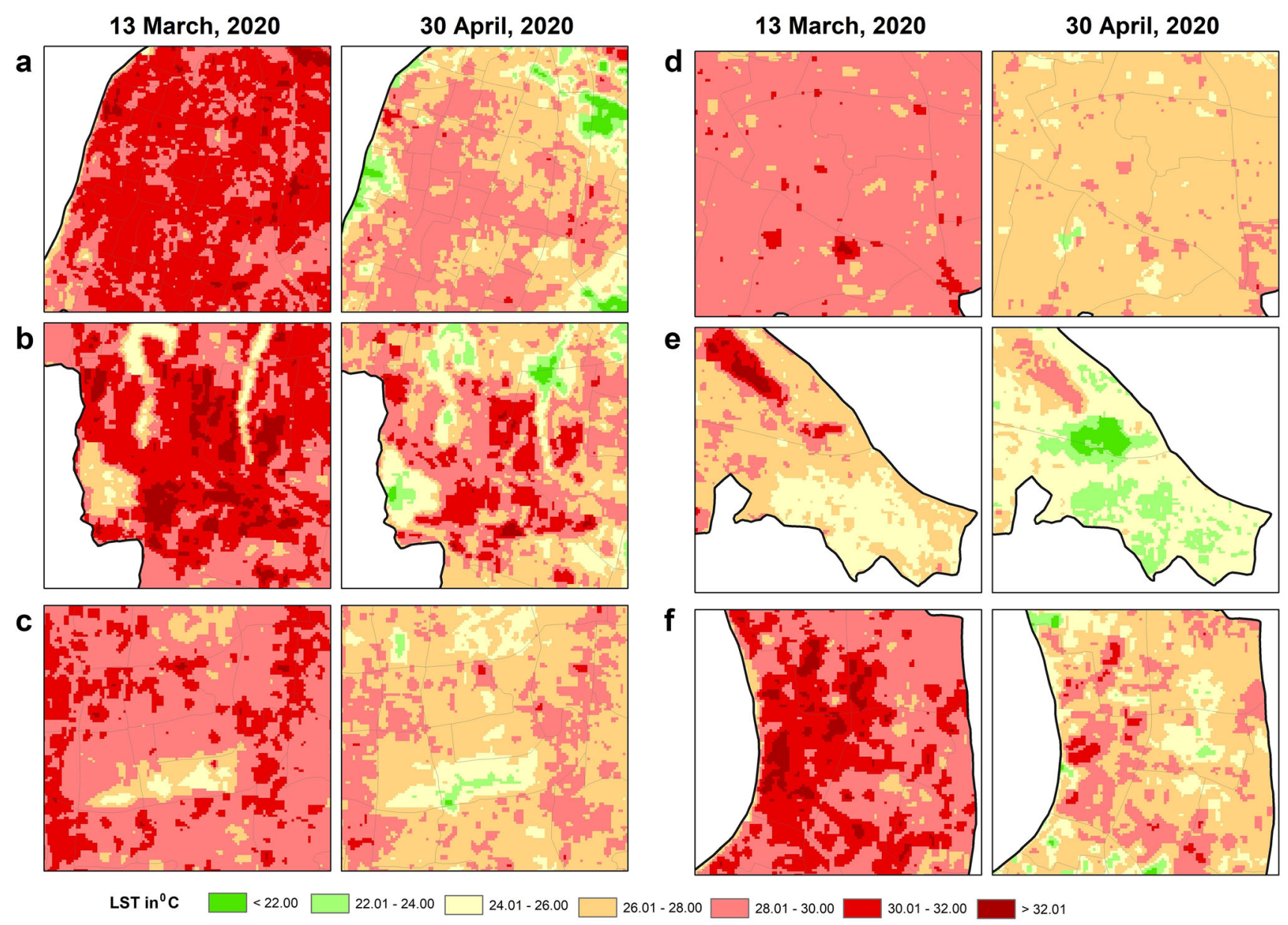

Fig. 9 Changes of LST from pre-lockdown to post-lockdown period in different parts of the city. a Zone 1, b zone 2, c zone 3, d zone 4, e zone 5 , and $\mathbf{f}$ zone 6

Kolkata, which is distributed between two wards, ward no. 58 and ward no. 108 (Fig. 9e). This is the location of famous East Kolkata Wetland which is located in ward no. 58. This wetland is a complex of natural and manmade wetlands and cover 125 square kilometers including salt marshes and salt meadows, as well as sewage farms and settling ponds. This is designated a "wetland of international importance" under the Ramsar Convention on 19th August, 2002. The other important neighborhoods are Tangra, Dhapa and Bantala. Tangra is located upon marshy and reclaimed low-lying land, is the home of over 350 tanneries. Dhapa is the area which consists landfill sites where the solid wastes of the city are dumped. Garbage Farming is a common practice in the landfill sites which produces 40 percent of the green vegetables in the Kolkata markets. Bantala houses Kolkata Leather Complex spread over an area of 450 hectares, along with IT SEZ. Residential areas are spread across this area, in accordance to industry, wetland and dumping ground. During lockdown period, LST ranges from 22 to $30{ }^{\circ} \mathrm{C}$ observed in this area which is $24-32{ }^{\circ} \mathrm{C}$ pre-lockdown period. Zone 6 is located in North Kolkata, which is the part of ward no. 1 to ward no. 12 (Fig. 9f). The neighborhood of this area is Cossipore, Sinthee, Chitpur, Bagbazar, Hatibagan, Shyambazar, Shobhabazar etc. These are the oldest area of Kolkata city which was urbanized during East India Company rule. There are a range of land use variations in this area, which is ranging from residential, commercial, transport and industrial land use. High density of residential, transportation and commercial activities are the reason for high LST. Surface temperature is coming to an ease during lockdown, where it was ranging from 24 to $30{ }^{\circ} \mathrm{C}$ with small pockets of high and low temperatures.

\section{Conclusion}

The rise of temperature at the global city is a major environmental threat around the globe. The rapid urbanization increased the pollution level of the city and it also influences the atmospheric temperature as well as LST. The COVID-19 pandemic and related lockdown worldwide has been reduced 
the pollution level. The significant impact observed in the major megacities of the world. The lockdown due to COVID-19 pandemic in the country, the pollution level of the city drastically improved. The decline of pollution level influences the LST in the city. The study aimed to analyze the impact of lockdown due to COVID-19 pandemic on the LST in the city. Single-channel algorithm used to retrieve LST from Landsat TM satellite data. Pre-lockdown and postlockdown atmospheric pollutants data and satellite imageries used to investigate the impact of COVID-19 pandemic on changes of LST. Air quality index (AQI) in different parts of the city estimated based on seven air pollutants such as $\mathrm{PM}_{2.5}, \mathrm{PM}_{10}, \mathrm{NO}_{2}, \mathrm{NH}_{3}, \mathrm{SO}_{2}, \mathrm{CO}$ and Ozone. The result indicates that the pollution level and LST significantly declined after lockdown in different parts of the city. The reduction of LST and atmospheric pollution can improve the ecological stability and habitat in the city.

Funding None.

Availability of data and material Data should be made available on request.

\section{Compliance with ethical standards}

Conflict of interest The authors declares that they have no conflict of Interest.

Ethical standards This manuscript is an original work and has not been published or considered for publication anywhere.

\section{References}

1. Kern, K., \& Bulkeley, H. (2009). Cities, Europeanization and multi-level governance: Governing climate change through transnational municipal networks. Journal of Common Market Studies, 47(2), 309-332.

2. Bulkeley, H., \& Betsill, M. (2003). Cities and climate change: Urban sustainability and global environmental governance. London: Routledge.

3. Bulkeley, H., \& Kern, K. (2006). Local government and the governing of climate change in Germany and the UK. Urban Studies, 43(12), 2237-2259.

4. Alber, G., \& Kern, K. (2008). Governing climate change in cities: modes of urban climate governance in multi-level systems. In OECD International Conference, 'Competitive Cities and Climate Change', 2nd Annual Meeting of the OECD Roundtable Strategy for Urban Development, 9-10 October. Milan: Italy.

5. Harvey, L. D. D. (1993). Tackling urban $\mathrm{CO}_{2}$ emissions in Toronto. Environment, 35(7), 16-20; 38-44.

6. Lambright, W. H., Stanley, A. C., \& Harvey, L. D. D. (1996). Urban reactions to the global warming issue: Agenda setting in Toronto and Chicago. Climatic Change, 34, 463-478.

7. Betsill, M. (2001). Mitigating climate change in US cities: Opportunities and obstacles. Local Environment, 6(4), 393-406.
8. Davies, A. (2005). Local action for climate change: Transnational networks and the Irish experience. Local Environment, 10(1), $21-40$.

9. Alam, M., \& Rabbani, M. D. G. (2007). Vulnerabilities and responses to climate change for Dhaka. Environment and Urbanization, 19, 81-97.

10. Pu, R., Gong, P., Michishita, R., \& Sasagawa, T. (2006). Assessment of multi resolution and multi-sensor data for urban surface temperature retrieval. Remote Sensing of Environment, 104(2), 211-225.

11. Jin, M. (2004). Analysis of land skin temperature using AVHRR observations. Bulletin of the American Meteorological Society, 85(4), 587-600.

12. Dickinson, R. E. (1994). Satellite systems and models for future climate change. In A. Henderson (Ed.), Future climates of the world: A modelling perspective. Amsterdam: Elsevier.

13. Becker, F., \& Li, Z. L. (1995). Surface temperature and emissivity at various scales: Definition, measurement and related problems. Remote Sensing Reviews, 12, 225-253.

14. Hall, F. G., Huemmrich, K. F., Goetz, S. J., Sellers, P. J., \& Nickeson, J. E. (1992). Satellite remote sensing of surface energy balance: Success failures, and unresolved issues in FIFE. Journal of Geophysical Research, 97, 19061-19089.

15. Aires, F., Prigent, C., Rossow, W. B., \& Rothstein, M. (2001). A new neural network approach including first-guess for retrieval of atmospheric water vapor, cloud liquid water path, surface temperature and emissivities over land from satellite microwave observations. Journal of Geophysical Research, 106, 14887-14907.

16. Bhattacharya, B. K., Mallick, K., Patel, N. K., \& Parihar, J. S. (2010). Regional clear sky evapotranspiration over agricultural land using remote sensing data from Indian geostationary meteorological satellite. Journal of Hydrology (Amst), 387(1-2), $65-80$.

17. Dash, P., Göttsche, F. M., Olesen, F. S., \& Fischer, H. (2002). Land surface temperature and emissivity estimation from passive sensor data: Theory and practice-Current trends. International Journal of Remote Sensing, 23(13), 2563-2594.

18. Friedl, M. A. (2002). Forward and inverse modeling of land surface energy balance using surface temperature measurements. Remote Sensing of Environment, 79(2-3), 344-354.

19. Dewan, A., \& Corner, R. (2013). Dhaka megacity: Geospatial perspectives on Urbanisation, Environment and Health. Berlin: Springer.

20. Morabito, M., Crisci, A., Messeri, A., Orlandini, S., Raschi, A., Maracchi, G., \& Munafò, M. (2016). The impact of built-up surfaces on land surface temperatures in Italian urban areas. Science of the Total Environment, 551, 317-326.

21. Pal, S., \& Ziaul, S. (2016). Detection of land use and land cover change and land surface temperature in English Bazar urban centre. The Egyptian Journal of Remote Sensing and Space Science, 20(1), 125-145.

22. World Bank Annual Report. (2007). The World Bank, Washington DC, USA. ISBN 978-0-8213-7240

23. Smith, C., \& Levermore, G. (2008). Designing urban spaces and buildings to improve sustainability and quality of life in a warmer world. Energy Policy, 36(12), 4558-4565.

24. Ziaul, S., \& Pal, S. (2018). Analyzing control of respiratory particulate matter on land surface temperature in local climatic zones of English bazar municipality and surroundings. Urban Climate, 24, 34-50.

25. Park, C., Schade, G. W., Werner, N. D., Sailor, D. J., \& Kim, C. H. (2016). Comparative estimates of anthropogenic heat emission in relation to surface energy balance of a subtropical urban neighbourhood. Atmospheric Environment, 126, 182-191. 
26. World Health Organisation. (2020). Media briefing on COVID19. March 13, 2020. https://www.pscp.tv/w/1LyxBNIZOAyxN. Accessed 5 May 2020.

27. Ministry of Health and Family Welfare. GOI. www.mohfw.gov. in. Retrieved 5 May 2020.

28. Economictimes.indiatimes.com. (2020). Retrieved from https:// economictimes.indiatimes.com/news/politics-and-nation/indiahad-6-4-million-cases-of-coronavirus-by-early-may-showsicmrs-sero-survey/articleshow/78051073.cms

29. EduKare Bulletin (2020). Retrieved from https://edukareonline. in/bulletin/articles/red-zones-containment-zones/

30. Jiménez-Muñoz, J. C., \& Sobrino, J. A. (2003). A generalized single-channel method for retrieving land surface temperature from remote sensing data. Journal of Geophysical Research, 108, 4688-4695.

31. Wan, Z. M., \& Dozier, J. (1996). A generalized split-window algorithm for retrieving land-surface temperature from space. IEEE Transactions on Geoscience and Remote Sensing, 34(4), 892-905.

32. Prata, A. J. (1993). Surface temperatures derived from the advanced very high resolution radiometer and the along track scanning radiometer. 1. Theory. Journal of Geophysical Research, 98, 16689-16702.

33. Rozenstein, O., Qin, Z., Derimian, Y., \& Karnieli, A. (2014). Correction: Rozenstein, O., et al. Derivation of land surface temperature for Landsat-8 TIRS using a split window algorithm. Sensors 2014, 14, 5768-5780. Sensors (Basel, Switzerland), 14(6), 11277

34. Gosain, A. K., Sarraf, M., \& Roy, S. (2012). A megacity in a changing climate: The case of Kolkata. Climate Change, 116, 7-8.

35. WBPCB (2003) Green governance newsletter. West Bengal Pollution Control Board, Kolkata, Vol. IV(I)

36. Bhaumik S (2007) Air pollution suffocates Calcutta. BBC News. Available online: https://news.bbc.co.uk/2/hi/south Asia/ 6614561.stm. Accessed on 3 May 2007.

37. KEIP-Kolkata Environmental Improvement Project. (2007). Sewerage and drainage master plan for Kolkata City. Kolkata Municipal Corporation, Consulting Engineering Services (I) Pvt. Ltd. Stup Consultants Pvt. Ltd. Ghosh, Bose \& Associates Pvt. Ltd. Dhi Water \& Environment.

38. Sen, D. (2013). Real-time rainfall monitoring and flood inundation forecasting for the city of Kolkata. ISH Journal of Hydraulic Engineering, 19, 137-144.

39. Gupta, A. K., Karar, K., Ayoob, S., \& Kuruvilla, J. (2008). Spatio-temporal characteristics of gaseous and particulate pollutants in an urban region of Kolkata, India. Atmospheric Research, $87,103-115$.

40. Gupta, A. K., Nag, S., \& Mukhopadhyay, U. K. (2006). Characterization of PM10 and benzene soluble organic fraction of particulate matter in urban area of Kolkata, India. Environmental Monitoring and Assessment, 115, 205-222.

41. Yadav, V., \& Bhagat, R. B. (2016). Spatial dynamics of population in Kolkata urban agglomeration. In R. B. Singh (Ed.), Urban development challenges, risks and resilience in asian mega cities (pp. 157-174). New York: Springer.

42. Mujabar, S., \& Rao, V. (2018). Estimation and analysis of land surface temperature of Jubail Industrial City, Saudi Arabia, by using remote sensing and GIS technologies. Arabian Journal of Geoscience, 11, 742 .

43. Qin, Z.-H., Karnieli, A., \& Berliner, P. (2001). A mono-window algorithm for retrieving land surface temperature from Landsat TM data and its application to the Israel-Egypt border region. International Journal of Remote Sensing, 22(18), 3719-3746.
44. Hook, S. J., Gabell, A. R., Green, A. A., \& Kealy, P. S. (1992). A comparison of techniques for extracting emissivity information from thermal infrared data for geologic studies. Remote Sensing of Environment, 42, 123-135.

45. Li, Z.-L., Tang, B. H., Wu, H., Ren, H., Yan, G., Wan, Z., et al. (2013). Satellite-derived land surface temperature: Current status and perspectives. Remote Sensing of Environment, 131, 14-37.

46. Bendib, A., Dridi, H., \& Kalla, M. A. (2016). Contribution of Landsat 8 data for the estimation of land surface temperature in Batna city. Eastern Algeria: Geocarto International.

47. Mahato, S., \& Pal, S. (2018). Changing land surface temperature of a rural Rarh tract river basin of India. Remote Sensing Applications: Society and Environment, 10, 209-223.

48. Chatterjeea, R. S., Singha, N., Thapaa, S., Sharmaa, D., \& Kumar, D. (2017). Retrieval of land surface temperature (LST) from landsat TM6 and TIRS data by single channel radiative transfer algorithm using satellite and ground-based inputs. International Journal of Applied Earth Observation and Geoinformation, 58, 264-277.

49. Landsat Project Science Office (2002) Landsat 7 Science Data User's Handbook. NASA's Goddard Space Flight Center, Greenbelt, 186p. https://landsathandbook.gsfc.nasa.gov/pdfs/ Landsat7_Handbook.pdf

50. USGS (2015) Landsat 8 (L8) Data users handbook. Department of the Interior, U.S.Geological Survey (USGS) (LSDS-1574, Ver. $1.0,106 \mathrm{p}$.

51. Artis, D. A., \& Carnahan, W. H. (1982). Survey of emissivity variability in thermography of urban areas. Remote Sensing of Environment, 12, 313-329.

52. Rhinane, H., Hilali, A., Bahi, H., \& Berrada, A. (2012). Contribution of Landsat data for the detection of urban heat islands areas Case of Casablanca. International Journal of Geographical Information, 04, 20-26.

53. Ott, W. R. (1978). Environmental indices theory and practice (p. 48106). Ann Arbor: Ann Arbor Science Publishers Inc.

54. CPCB (2015) National Air Quality Index, Central Pollution Control Board, Ministry of Environment, forest and climate change. Data retrieved from https://app.cpcbccr.com/ccr/\#/ caaqm-dashboard-all/caaqm-landing. 31 Mar 2020.

55. Mahato, S., Pal, S., \& Ghosh, K. G. (2020). Effect of lockdown amid COVID-19 pandemic on air quality of the megacity Delhi, India. Science of the Total Environment, 730, 139086.

56. McFeeters, S. K. (1996). The use of the Normalized Difference Water Index (NDWI) in the delineation of open water features. International Journal of Remote Sensing, 17(7), 1425-1432.

57. Mukherjee, S., Bebermeier, W., \& Schütt, B. (2018). An overview of the impacts of land use land cover changes (1980-2014) on urban water security of Kolkata. Land, 7(91), 1-25.

58. Sutton, M. A., Place, C. J., Eager, M., Fowler, D., \& Smith, R. I. (1995). Assessment of the magnitude of ammonia emissions in the United Kingdom. Atmospheric Environment, 29(12), 1393-1411.

59. Kean, A. J., Harley, R. A., Littlejohn, D., \& Kendall, G. R. (2000). On-road measurement of ammonia and other motor vehicle exhaust emissions. Environmental Science and Technology, 34(17), 3535-3539.

60. Kirchner, M., Braeutigam, S., Feicht, E., \& Löflund, M. (2002). Ammonia emissions from vehicles and the effects on ambient air concentrations. Fresenius Environmental Bulletin, 11(8), $454-458$.

Publisher's Note Springer Nature remains neutral with regard to jurisdictional claims in published maps and institutional affiliations. 